\title{
REVIEW
}

\section{DIVING INTO THE CONTEXTS OF IN-BETWEEN WORLDS: WORLDMAKING IN MEDICAL TOURISM}

\author{
TOMAS MAINIL, ${ }^{*} \dagger$ VINCENT PLATENKAMP,$*$ and HERMAN MEULEMANS $\dagger$ \\ *Centre for Cross-Cultural Understanding (CCU), NHTV Breda University of Applied Sciences, \\ Breda, the Netherlands \\ $†$ Research Centre for Longitudinal and Life Course Studies (CELLO), University of Antwerp, \\ Antwerp, Belgium
}

\begin{abstract}
In this review article, the authors contextualize the contemporary practice of medical tourism in terms of the concept of worldmaking, which was introduced (in this journal) with two articles a year or two ago by Hollinshead. Here, the authors first contextualize medical tourism in terms of "worldmaking" per medium of the observations of the corporeal realms identified by Alexis de Tocqueville almost 200 years ago. In 1835, de Tocqueville wrote with enthusiasm tinged with nostalgic regret about the new world of American democracy that he then saw as the world of the future. A serious rupture in history took place of which he became a most relevant critic. But there have been (according to Mainil, Platenkamp, and Meulemans) many ruptures since then: that is, there have been short periods of "in-between worlds" that became ever more anchored in the timeline of Western history. Today, they argue that tourism as a field of expertise, practice, and knowledge is intertwined with several other networks of expertise. It is responsible (itself) for many small "ruptures" in these modern times. Mass tourism can be seen as such a shift. Sustainable tourism and the attention paid to climate change would be another such shift. And the authors of this review argue that an interesting and deep-seated case in this regard is medical tourism. They argue here that medical tourism has a great deal of worldmaking capacity, especially by means of the Internet and international marketing tools. It arises in the interstices of the interacting networks of a global world. It crosses borders in line with emerging power structures in a global network, but it also meets local resistance or regional obstacles that are related to other networks. In between these worlds of human experience, various interactions of perspectives on the concept of health itself come to the surface. Within the field of medical tourism different stakeholders play a role in a worldmaking process. Our reviewers from the Low Countries thereby argue that medical tourism itself is responsible for a Tocquevillean rupture within and across our global network society. In their view, medical tourism also constitutes a new hybrid - that is, as a hybrid medical paradigm
\end{abstract}

\footnotetext{
Address correspondence to Tomas Mainil, Lecturer in Research Methodology and Researcher at Centre for Cross-Cultural Understanding (CCU), NHTV Breda University of Applied Sciences, Breda, the Netherlands. Tel: 0032477941932; E-mail: Mainil.t@ nhtv.nl
} 
that seems to be appearing within the performative and productive world of tourism. (Abstract by the Reviews Editor, Keith Hollinshead)

Key words: Worldmaking; Rupture; In-between worlds; Hybridity; Medical tourism; Network society; Enunciation

\section{Network Society and In-Between Worlds}

During the 19th century the French aristocrat de Tocqueville made a thorough analysis of the emerging democracy of the New World (1835, $1840,1968)$. In his analysis it repeatedly appears that he regards himself as living in between two historical eras, the old aristocratic age and the new democratic age. He viewed this position as promising in its unique opportunities to analyze both worlds from "the other perspective." Being raised in and impregnated by the values, convictions, and conventions of the aristocratic European old world, de Tocqueville embraced (with some pangs of nostalgic regret) this new world of American democracy that he saw as the world of the future. A serious rupture in history took place of which he became a most relevant critic. But ruptures have only increased since then. Adapting Foucault's framework in his histories of punishment (1975), madness (1961), the rise of a new medical gaze (1963), the history of sexuality $(1976,1984 a$, 1984b), or of knowledge itself (1969) to our network society, one observes that short periods in history of "in-between worlds" have become more anchored in the Western world than ever. After these short periods-according to Foucault (1975) - at the start of the 19th century a drastic process emerged of disciplining society in all these and other areas of everyday life. In schools, on the labor market, and in tourism the same process of "disciplinization," which marked the new modern era, seemed to take place after this short period of rupture that preceded these revolutionary changes. (See Table 1 for glossary of terms used.)

In the history of science, as it has been analyzed by Kuhn (1962), Lakatos (1965), Latour (1987), Bourdieu (2004) inter alia, the same picture appears to the mind: in a short period of time the epistemological grid changes drastically during a revolutionary stage of abnormal science in which the social context plays an important role in understanding the "growth of knowledge." After this process the grid takes another turn: Newton's theories dominated physics for more than 300 years before giving way to Einstein's and Bohr's theories after this rupture. In this short period, too, the space of an "in-between world" plays a crucial role during these ruptures in power and knowledge constellations. It all seems to happen in a short period of time during which an enormous outbreak of uncertainty and creativity lies underneath the everyday life experiences of its participants. Tourism as a modern field of practice and knowledge could be seen as a creator of ruptures within a global market perspective.

Certainly in modern and postmodern life, worldmaking - in its pure form, the creative power to enhance new decisive ruptures-constitutes an important part of the outburst of creativity from these "in-between worlds." de Tocqueville referred to it in his analysis of the rise of American democracy. At the eve of World War I a famous and creative center of art and philosophy in Vienna reflected on its position and created new forms of thought and imagination. San Francisco, California (Hannerz, 1993) was such a center during the 1960s where "alternative" lifestyles were being tested as in Copenhagen, Paris, London, and Amsterdam. More ruptures in various areas of everyday life seemed to emerge in a new era that many started to call postmodernity. Postmodernity became synonymous with a chaotic universe where different "worlds" coexisted next to one another. This coexistence was not always characterized by peace and harmony. Many interactions between these "worlds" were possible. They could clash and end in serious conflicts like the "generation gap" or the sexual revolution, they could merge into "third cultures" (Featherstone, 1990), and they could take any form of hybrid interaction (Hollinshead, 1998) in between these extremes. Characteristic of all these types of interaction is that the phenomenon of a rupture became a crucial 
Table 1

Glossary of Terms

$\begin{array}{ll}\text { Medical gaze: } & \begin{array}{l}\text { The dominant medical perspective that came into existence around } 1800 \text { in the hospitals of the West } \\ \text { (Urry's "tourism gaze" has been based on this). }\end{array} \\ \text { Disciplinization } & \begin{array}{l}\text { According to Foucault the main principle that dominated in the Western system of punishment, hospi- } \\ \text { tals, psychiatric institutions, schools, and others. Through it people became controlled and "normalized" } \\ \text { in their behavior. } \\ \text { The place where people inhabiting two different cultures interpret each of the two cultures they are part } \\ \text { of. }\end{array} \\ \text { Third cultures } & \text { Cultures that emerge through a fusion of cultural elements from different cultures. } \\ \text { Verstehen } & \begin{array}{l}\text { A method that tries to understand something as a meaningful element in its coherent context. As the } \\ \text { method form the geisteswissenschaften often opposed the "explanations" of the natural sciences. }\end{array} \\ \text { Enunciated } & \begin{array}{l}\text { Evoked, derived from the french "énoncé," which is a core element of knowledge that has been evoked } \\ \text { (enunciated) during the activities of the archeologist of knowledge, Foucault. }\end{array} \\ \text { Episteme } & \begin{array}{l}\text { Greek for "knowledge." According to Foucault the "in-depth" structure of knowledge. } \\ \text { Distanciates }\end{array} \\ \text { A crucial problem with "perspectivism" is how to relate introspective perspectives with ones that are } \\ \text { created from a (scientific) distance or "distanciated" (see Paul Ricoeur). }\end{array}$

element to be taken into consideration. This also implied that "in-between worlds" and the eruption of a process of worldmaking have been multiplied with it. The world of tourism is intertwined with several other global arenas; it could be considered as a marker of interactional liaisons of multiple actors.

\section{The Proliferation of Worldmaking in a Network Society}

Giddens (1991) refers to modernity as a risk culture in which reflexivity and reskilling, based on local knowledge of day-to-day life, are combined with systems of accumulated expertise with its disembedding and deskilling influences. These systems act to transform the content and nature of day-to-day social life while at the same time modern people are getting used to reflecting on the risks of this same social life. Nevertheless, Giddens (1991) does not mean by this that social life is inherently more risky than it used to be: "for most people in the developed societies this is not the case" (p. 3).
This statement and others indicate that Giddens, like Habermas and Foucault, limits his observations to developed societies, omitting the rest of the world. If one desires to attempt to include the rest of the world, a first point of reference must be the even bigger tension between the global and the local than Giddens, Habermas, and Foucault have elaborated on in their writings. The abstract systems of Giddens penetrate in different ways into the local, regional, and national lives of the non-Western world. Disembedding processes by the expansion of abstract systems, like money and power, do influence the rest of the world, but not in the same way. For a long time tourism has been seen as the appendix of a neocolonial plantation economy in which the rich West once again dominates the poor Southern hemisphere. Recently, however, Boissevain (1996) points to a reverse movement as well. Through tourists' growing interest in local cultures, modernization through tourism does not only imply the subsequent destruction of these cultures. Often a revival of previously forgotten cultural elements, like lo- 
cal dances or food, follows this foreign attention to the local culture at the same time. From within the context of local cultures themselves always a reaction to globalizing influences takes place that needs our understanding as well. People are not just passive recipients of globalization, but react actively to it from within their local contexts. The strength of this reaction, of course, depends also on the dominating discourses and counterdiscourses in any region.

Bali has a long and strong local tradition of assimilating new elements in its rich culture. Therefore, the disembedding process of touristification of Bali (Picard, 1996) is not self-evident because of the actual business influence of tourism interests. Is there, or not, boundary maintenance? Or more specifically, are the Balinese able to distinguish clearly between that which they sell to tourists and that which they reserve for themselves, between their religious ceremonies and the commercial performances derived from them?

Giddens (1991) especially knows that in late modernity "a plurality of choices prevails" (p. 219). The point here is that this Western plurality must be rethought in a confrontation with the rest of the world whereby this plurality might be problematized in other, non-Western contexts when transmitted to the tension between the global and the local. In the work of Foucault this transmission is not addressed. The individualizing disciplining of modern Western hospitals, prisons, schools, armies, and labor markets, as described by Foucault cum suis, obviously does not take place in the same way in the rest of the world. It takes elaborate research into non-Western backgrounds to come to sophisticated conclusions on the various sorts of disciplining in other parts of the world. At the same time the expansion of these abstract systems "creates increasing quanta of power-the power of human beings to alter the material world and transform the conditions of their own actions" (Giddens, 1991, p. 138). Foucault, in a rather similar way although with much less attention to human agency, refers to counterdiscourses as present but not dominant enough in modern life. Here, too, the analyses of Habermas, Foucault, and Giddens do not suffice to explore the growing complexity in the tension between the global and the local expressed by many new voices, and the plu- ral reactions in various forms from diverse (colliding? Intersecting?) networks all over the globe. For example, oral traditions in Africa may change over time into a new orality of the postcolonial city:

It were the pavements, the squares, the village neighbourhoods and the rundown fringes of the city that elaborated and transmitted this new form of orality that I shall term 'urban': the word inscribed, drawn, on the walls of Mogadishu, the word spread by pavement radio in Kinshasa, the satirical word, traded like goods, in the market place of Lomé. This return of orality and its shift from the country to the city is one of the new signs of contemporary Africa and its strategies of identity. (Allessandro Triulzi, cited in Chambers \& Curts, 1996, p. 78)

Where different encounters of Western and non-Western worlds have to be taken seriously, this proliferation of worldmaking from within "inbetween worlds" could provide us with an interesting and relevant source of information about how to understand these new circumstances. This implies that worldmaking within "in-between worlds" should be reviewed on the global scale of a network society (Castells, 2000). More specifically, the need for a reorientation of dominant Western perspectives is highlighted here.

For decades, anthropologists like Clifford Geertz $(1983,1993)$ have spoken about an "interpretive turn" in anthropology. By this they turn again to the long tradition of Verstehen that has been marginalized too long in some main anthropological streams of thought. This turn also accentuated a change in the anthropological attitude from a distant professional who analyzed cultures in terms of functions and dysfunctions to an involved interpreter who tried to understand meanings. James Clifford (1986), in his reaction to the "pastoral tendency" among anthropologists, wants to go even further. He feels that the professionalism of the fieldworker-whether or not engaged in interpreting his data-has to be relativized in view of the other relevant voices of a local culture. This relativizing critique breaks with the original attitude of the mostly Western and logocentric, social scientist as the ultimate, neutral, and objective assessor of local cultures as a whole. There is not one objective researcher in control; many, often non-Western, voices need to be heard in order to 
generate better, objectified knowledge but also to include a more normative discussion on plural values and convictions that interfere with that knowledge.

Another example of this reorientation of Western perspectives from within in-between worlds stems from Spivak's analysis (1999) of Marx's "Asiatic mode of production." Spivak relocates the intentions of this analytical category by inferring the "native informant's" point of view. By this she creates a more diverse picture of what happened in this part of the non-Western world than Marx and his followers were able to. In the same way she criticizes the Northern/Western European feminist who (dismisses? patronizes?) her Southern sister as a "native informant" by sharing the male tendency to establish the Western European subject as the dominating one. Gradually a more modest and refined kind of professionalism has been announced in our global village to which the answer of a proliferation of diverse local (counter)discourses seems more than logical alone. The exclusion of local perspectives that remain hidden in in-between worlds could be considered as one of the most threatening developments to a culturally diverse human existence yet to be explored.

\section{Postcolonial Perspectivation in a New Epistemological Space?}

This world is a complex network society in which there is not one principal coherent, predominant discourse as a new totality, as Foucault has argued in his writings. Instead, diverse perspectives are enunciated in the same space of knowledge. Pluralism is a conditio sine qua non for an academic discussion of the new network society. In this sense, Foucault's episteme still has a Western flavor that can now be dispensed with. Another important objection to the archeology or genealogy of Foucault is its relativism. In a network society relativism is not an answer to the differences between perspectives. There is always a need to confront perspectives from a background of universal understanding. Diverging perspectives will never be understood as isolated wholes that are immune to critique from the outside.

Although there is some vagueness in the Fou- caldean concept of episteme, the usefulness of the idea behind it for our purposes goes without saying. A postcolonial "episteme," as circumscribed by Hall and du Gay (1996), makes sense considering the often still hidden colonial influences in various forms of sociological, anthropological, and philosophical thinking. Hall relates the resistance to these colonial influences in our globalizing world with its varying networks to this new discursive field, which he calls "postcolonialism."

In a postcolonial way of thinking all parties involved have gone through the phase of colonial relationships, are (aware of? delivered from?) its frustrations, and are supposed to have arrived at a new understanding of the emergent economic, political, and cultural networks around them. This new understanding distanciates itself from the former compulsion of the colonized to return a voyeuristic gaze upon Europe, away from the longing of the East for conquest of the West because this longing requires a simultaneous disowning of the world that has been colonized. In colonial education this same longing for the world of the conqueror has been institutionalized; this whole process should be understood by both postcolonizers and postcolonized in order to recover from it. Still, in our days, Western observers tend to neglect their ancestors' colonial past. This seems a logical reaction in view of what "selves" do in late modernity: "avoidance of dissonance forms part of the protective cocoon which helps maintain ontological security" (Giddens, 1991, p. 188).

This also remains true for many Westerners in their relations with the non-Western world. Tourism offers good examples in this respect. Many Western visitors from the former colonizing nations travel around in their "environmental bubble" (Cohen, 1979) in which they want a secure and pampered treatment and certainly no harsh confrontations with their non-Western hosts.

As Bhabha (1994) states, the culture of Western modernity with its carefully maintained ontological security must be relocated from a postcolonial perspective. The pastoral tendency in cultural anthropology has been unmasked as the projection of a so-called overcivilized Western society. Now the time has come to relocate this tendency by means of various postcolonial perspectives. In a comparable way Spivak criticizes the narcissism 
of the liberal-feminist investigator who gazes at the silenced Third World women without hearing them represent themselves (Spivak, 1987, p. 41). It all ends, according to Spivak, with a solipsistic confirmation of the investigator's discursive privilege. In criticizing the French feminist writer Julia Kristeva, Spivak states that "her question, in the face of those silent women, is about her own identity rather than theirs" (p. 137).

This, of course, does not imply the preconceived rightness of a so-called "Third World" perspective. In the words of Castells, in feminist literature the end of patriarchalism has been proclaimed and the nuclear family of modern times is partly replaced by a proliferation of various types of households. But there has also emerged a considerable body of literature on the position of women from the southern hemisphere, written by themselves. In this literature various perspectives are demonstrated in diverse circumstances of power relations from different parts of the world.

The fundamental task of feminism, says Castells, remains here to de/reconstruct woman's identity by degendering the institutions of society through struggles and discourses. It leads to the construction of many identities that seize micropowers in the worldwide web of life experiences. This also implies the voices of women from various contexts other than the dominating liberal Western voice presented as universal. The question therefore emerges how the legitimating narratives of cultural domination can be displaced to reveal a "third space" (Bhabha, 1994). According to Bhabha, in this third space there is a need for a theory of hybridity (Bhabha, 1994; Hollinshead, 1998), in which room will be made for new, emergent voices and the translation of social differences that goes beyond the polarities of Self and Other, East and West. In a postcolonial order this also implies that previously silenced or silent voices enter the academic and professional discourses from their local perspectives in between the global and the local, from many in-between worlds. In a third space, therefore, different traditions meet with their fusing, clashing, or interacting visions on moral and existential themes that are often excluded from official discourses.

From within worlds that have been constituted by these various interactions of local, regional, national, global deterritorialized or virtual networks-social structures-in one and the same place such as an international tourism destination, perspectivation is produced in the sense described by Hannerz (1993). People, according to Hannerz, "manage meanings from where they are in the social structure" (p. 68) and perspectivation is the social organization of meaning in a network of perspectives. The perspectivation of meaning is "a powerful engine in creating a diversity of culture within the complex society. Call the network a polyphony, as the perspectives are at the same time voices; term it a conversation, if it appears fairly low-key and consensual; refer to it all as a debate, if you wish to emphasize contestation; or describe it as a cacophony, if you find mostly disorder" (Hannerz, 1993, p. 68). And it is this perspectivation that reminds us of the process of worldmaking from within in-between worlds in networks on a global scale.

\section{Pluralistic Worldmaking in a Network Society}

Worldmaking is a discursive practice in the first place. As Foucault (1975) stated in his Surveiller et punir, speaking of the rise of a new, discursive world of punishment around 1800:

An entire whole of appreciative, diagnostic, prog-
nostic and normative judgements about the crimi-
nal individual came to live in the shell of the pe-
nal laws. Another truth has penetrated the one
that was demanded by the judicial mechanisms:
a truth that, confusedly mixed at first, promoted
the confirmation of guilt to a strange scientific-
juridical complex. (p. 24, translated from the
French)

Two worlds meet in this passage, the old and the new. The new world is rising in a newly discovered discourse, while the old discourse is fading away. A few pages before he also observes:

the old partners of the juridical frame of punishment, body and blood, left their positions. A new figure entered the scene, masked. A certain tragedy was finished: a comedy started with silhouettes of shadow, disembodied voices, meticulous entities. The machinery of punitive justice must now grasp that reality without a body. (p. 22, translated from the French) 
This type of confrontation between discourses that constitute real worlds in everyday life (in this case, punishment) has been multiplied in this network society. For a good understanding of the process of worldmaking [bearing in mind the definition of Hollinshead (2009a); see also Hollinshead (2009b) and that shown in Table 1), a discursive analysis of what happens in the context of such confrontations seems highly recommendable. A significant problem with this context is that many voices seem to remain silent. However, this is not necessarily so, as there are counterdiscourses that do not enter the official, often Western or AngloSaxon dominated discourse. And there are many voices from within the contexts of many inbetween worlds that seem to be involved in a constant process of perspectivation that spans the globe. Too many "worlds" remain hidden for the insecure lenses produced by academic or professional discourses in tourism as elsewhere.

This is where worldmaking might enter the game, in the field of medical tourism. Medical tourism has the power to apply worldmaking in the sense described by Hollinshead (2009a, 2009 b) as a false imaginative process, but has also the chance of being a change agent in how countries deal with global health care provision and globalization itself. This is worldmaking in the positive sense of the word. The question therefore arises of how one can reach these perspectives that remain hidden in the contexts of this type of discourse. Moreover, how do these perspectives interact in between the global and the local? How does the concept of rupture play a role within the process of medical tourism?

\section{Medical Tourism, Before and During the proces de rupture}

People have traveled for health reasons since ancient times, but that was before medical tourism became global and subject to the momentum of today, where multiple stakeholders are working towards a global network of health-related services. As we know, the established idea of patients and their loved ones was to receive health care from the nearest medical institution, general practitioner, or medical specialist. This medical paradigm has evolved to allow the health user to choose providers for his needs on a broader basis. We have to acknowledge that medical and health care are becoming globalized. The global network society has touched the medical field and there is no going back. Health care was structured on a national level, but today we see other perspectives arising for the supply and demand side.

Medical tourism is an interesting case. It arises in the interstices of the interacting networks of a global world. It crosses borders in line with global power structures in a global network, but it also meets local resistances or regional obstacles, which are related to other networks. Because of the relation between the local and global networks, in the case of medical tourism, the positive worldmaking capacity could come into play, whereas the false imaginative process could become prominent or turned down. Within this complex situation puzzling contexts merge that require very close attention. In these contexts from in-between worlds various interactions of perspectives-for example, on the concept of health itself-come to the surface.

\section{Medical Tourism: Characteristics and Background}

Medical tourism could be considered as a boundary between health care provision and other business and knowledge fields:

\begin{abstract}
Medical tourism as a niche has emerged from the rapid growth of what has become an industry, where people travel often long distances to overseas countries to obtain medical, dental and surgical care while simultaneously being holidaymakers, in a more conventional sense. It has grown dramatically in recent years primarily because of the high costs of treatment in rich world countries, long waiting lists (for what is not always seen institutionally as priority surgery), the relative affordability of international air travel and favourable economic exchange rates, and the ageing of the often affluent post-war baby-boom generation. (Connell, 2005, p. 1094)
\end{abstract}

As this example suggests, we consider medical tourism as a process: the health user makes the argumentative choice to receive health care in a medical facility in another distant location. At that illustrative point - if the international patient does allow guidance - a process starts: medical tourism 
companies facilitate the journey and guide the trip throughout its tourist and medical character. Two different worlds come together: the high technological and expertise-based medical world and the quality service-based tourism field:

Ultimately 'tourism' is rather more than just a cosmetic noun for an activity that otherwise has little to do with conventional notions of tourism, since most visitors and certainly those who accompany them, find some time for tourism. Moreover, at the same time, the whole infrastructure of the tourist industry (travel agents, airlines, hotels, taxis etc) all benefit considerably from this new niche. Indeed, since for a significant proportion of patients there may be a lengthy period of recuperation, the rewards to the tourist industry, and especially the hotel sector, are considerable. (Connell, 2005, p. 1098)

The stakeholders in this field (Bourdieu, 2004) will have to cope with new doxas, typically present in the in-between world reality. A doxa is implicit and self-evident. It is what people in a particular life world or culture share and which goes without saying, it is a "adhesion to the presuppositions of the game" (Bourdieu, 2004, p. 111). When two distant knowledge fields collide with their own worldmaking capacities a new balance needs to be found. Out of the rupture new worldmaking scripts arise, which enlarge the fields of uncertainty in the in-between vacuum of globalized citizens today.

Medical tourism is one form of many globalizing health movements. Today it can be ascertained that health care is going global and that global health issues should be addressed in a worldwide integrated approach. However, there are many boundaries within the field of global health. One major agenda is based on providing medical and other aid to deprived areas, working in an international mode (World Health Organization, United Nations, NGOs). This movement has been in place for a long time and has been professionalized (United Nations Development Programme, 2010) with its own dynamics and issues. Within this reality a wide range of different political measures are taken, analysis of which falls outside the scope of this article. Another boundary is the emergence of cross-border health care, where patients travel short distances to neighboring countries because of positive factors related to the health system of that country. A major difference between it and medical tourism is that with cross-border health care, the idea of tourism production is lacking. The medical aspect is the most important factor. Health tourism could also be connected to health. However, it has more to do with global wellbeing - the provision of spa facilities and accompanying limited medical treatments. One could state that all globalizing health-related delivery could be put under the umbrella of transnational health-related services (THRS), with in the center the transnational health user (THU). Medical tourism does fit in this terminology, which seeks to develop into a blended taxonomy appropriate for several knowledge and business fields.

\section{Stakeholder Perspective Within Medical Tourism}

Medical tourism needs a stakeholder perspective. Considering medical tourism as a process also presupposes the idea that multiple gatekeepers play a role into the field. In the first place, there is the patient-traveler. The patient-traveler wants to finish his medical tourism tale with a positive and healthy vibe. However, in his quest for health he will find himself in an in-between world, traveling between his own cultural values and beliefs and those of the medical tourism destination. Next we have the medical institution, the medical tourism facilitator, and the homeland insurance company. They are the ones who are responsible for the worldmaking capacity of medical tourism as a process. Finally, we must not forget a fourth party who also has to deal with the reality of medical tourism: the local population who see the patients from developed countries profiting from the services provided. In what way do local citizens benefit or suffer from the reality of medical tourism? Globalizing health dynamics are causing "ruptures" because of the fact that the idea of receiving health care only locally has been abandoned by parts of the world population: "In less than a decade the rise of medical tourism has demonstrated that a form of service provision, the provision of health care, so labour intensive that it was assumed to be highly localised can now be globalised like so many other service activities" (Connell, 2005, p. 1099). 
But how are the stakeholders involved in different aspects of this rupture?

Future patients of medical tourism enter the inbetween worlds by using the Internet. Multiple websites on medical tourism show how great the possibilities are of visiting another country for medical purposes. They show the different operative procedures, together with pictures of facilities, hotels, and scenery. Via these websites the patient enters the field of medical tourism. It is in this way that the first contact is being made between medical tourism facilitators, medical institutions, and the future patient. This is how the process starts:

The health care travel packages typically include air and ground transportation, travel visas, hotel accommodations, assistance from a local company representative in the destination country, transfer of medical records to treating physicians, and negotiated rates for whatever medical procedures clients decide to purchase. (Turner, 2007, p. 1639)

In the best case scenario the patient will have preconsultations in the home country; afterwards he will visit this newly created world, where he will be guided by a medical tourism facilitator spokesperson and the medical staff of the treating institution, in between two worlds. In this way also a new world is created. The worldmaking capacity of medical tourism websites, facilitator companies, and medical institutions overseas goes without saying. However, medical tourism advocates indicate the unlimited opportunities for the individual seeking medical treatment: "with selfselected medical tourism the individual has control over his health care programme" (Bies, 2006, p. 1158).

The Internet could be seen as a worldmaking entity or as a means to accomplish that end. Within the context of medical tourism this is certainly the case because of the gatekeeper function of the medical tourism websites (Lunt, Hardey, \& Mannion, 2010). The first step to professional medical tourism practice will be these websites. Because these websites are linked to companiesmedical tourism facilitators - they are made as attractive as possible to gain future health users. There is no better way to show this worldmaking force by throwing some significant examples into the ring. There is a prominent body of knowledge on quality criteria of medical websites. Development of criteria for medical tourism websites could be an enrichment to professionalize this booming sector. Promoting their own capacities is one of the main worldmaking issues with these websites:

Cost Comparison-India vs United States of America (USA). Significant cost differences exist between U.K. and India also when it comes to medical treatment. India is not only cheaper but the waiting time is almost nil. This is due to the outburst of the private sector which comprises of hospitals and clinics with the latest technology and best practitioners. (Website 1, consulted 7/ 08/08; bold emphasis added)

The most prestigious medical centers that focus on medical tourism are state-of-the-art facilities. These medical centers have invested in the latest technology in laboratory, diagnostic and surgical facilities. The level of service in terms of nursing care is second to none with nurse-to-patient ratios approaching one-to-one. Leading overseas medical centers are run by highly proficient managers with international experience. (Website 2, consulted 7/08/08; bold emphasis added)

In addition to this promotional and marketing content these websites show also an array of medical information that is very descriptive, and often does not address alternative ways of managing disease; in other words, the future patient gets only one possible side of the medical story. It is also very difficult for the patient to verify the truth of the information found on these websites:

Example for gastric banding; advantages: • Lowest mortality rate $\bullet$ Least invasive surgical approach $\bullet$ No stomach stapling or cutting, or intestinal re-routing $\bullet$ Adjustable $\bullet$ Reversible $\bullet$ Lowest operative complication rate $\bullet$ Low malnutrition risk (Website 3, consulted 7/08/08)

This is just a small fraction of what is portrayed on medical tourism websites. However, it is clear that potential patients are subject to a whole new world. They are put in control of their own medical decisions, but are making choices based on information colored by its creators.

Medical tourism is becoming a global phenom- 
enon not least through the encouragement of many national governments. They see medical tourism as one solution to bolster the economic prosperity and development of their country. Medical tourism as a national solution has many aspects within its reality:

Countries that actively promote medical tourism do so for self-serving reasons. Investing in the medical industry is a way to increase gross domestic product, upgrade services, generate foreign exchange and create a more favourable balance-of-trade situation, and boost tourism. Other more subtle benefits include stemming a brain drain of health professionals and buying goodwill. (Ramirez de Arellano, 2007, p. 195)

Garud (2005) reported that the countries of Singapore, Thailand, and India were the busiest on the national policy level with regards to medical tourism initiatives: "In many countries, it is being actively promoted as an official government policy. The governments of Singapore and Thailand have been in the forefront in Southeast Asia and the Government of India is trying hard to catch up" (Garud, 2005, p. 318).

Today, however, this national supply governmental policy is a global phenomenon in which other countries in Asia, Central and South America, and Europe are beginning to play a role. The public policies in these countries are actively interfering or cooperating with private corporate companies, which makes medical tourism a public-private global alliance.

Medical tourism can only become a real global health solution if the local population of the specific medical tourism countries also benefit from the facilities and medical services provided. If this is not the case and a situation emerges where tourists from Western countries are the only ones who can aspire to these services, it could create the perception of medical tourism as medical colonization, which is not a desired outcome in the forum of global health discussions. In India (Garud, 2005; Hazarika, 2010), this present rupture between internationally oriented medical expertise and more limited access for the local population could harm the global health discussion. However, if national governments see medical tourism as a means of developing their national health care sys- tems this would weaken the rupture. A significant example can be observed in Thailand (Cohen, 2008). Further research needs to be developed on the local perspective in relation to medical tourism. In a first phase, this would need to have the character of research with an ethnographic turn. Analysis of how patients and local populations deal and cope with this new cluster of services should be researched with qualitative research methods. It is unlikely that these stakeholders would take in any useful information from a quantitative reflex. The limitations of survey methodology have been ascertained many times. Also, the concept that health behaviors are culturally determined would lead us to adapt an applied anthropological research design. This first phase would have to be executed by social scientists with attention and sensitivity for the life-world of the local citizen and health user.

\section{Globalization, Medical Tourism, and a New Cross-Cultural View of Health}

The effects of globalization and the network society are present today without a doubt in many areas of expertise and human contexts. Medical tourism beholds the global dimension as no other realism, which of course has its geographical consequences. With multiple stakeholders in its toolbox medical tourism will continue to expand:

Despite the risks, medical tourism is expected to
continue. Patients may no longer give a second
thought to traveling halfway around the world for
a procedure that is either not affordable or not
available at home"especially if it might save their
lives. And shopping for a surgical procedure
could eventually become as routine as trying to
find the best deal in airfare. (Newman, 2006,
p. 581)

However the combination of bringing together distant geographies by the different products medical tourism has to offer, could also lead to see the medical expertise as a field very much open for marketers and business opportunities. One could speak of a brave new world, although offering health care initially followed other definitions. Thus, the relationship between global health and medical tourism initiatives should be explored at the very least, and ideally worked through as well. 
The geographical omnipresence of medical tourism could be seen as a tool for in tackling equity issues to attain joint public and private goals.

Medical tourism as a global entity within a network society also affects the idea of getting health care in one's own cultural setting. One's own cultural field will enhance one's values and beliefs concerning health and care settings. However, when the home setting of health care is exchanged for a global setting, new cross-cultural experiences and skills come into play for patients and relatives, as well as for medical staff and supporting services. This also will create-certainly in the beginning - a rupture for patients and the supply side. However, out of this cultural struggle the new cross-cultural patient-citizen will arise and will acknowledge that global health care and medical tourism need a new cross-cultural way of thinking about medical care. American citizens who travel to Singapore for their health have to deal with cultural specificities of that country. Europeans who travel to Turkey for health reasons have to do the same. However, medical tourism medical staff and supporting services also need to make a cultural shift. This mutual cultural exercise is a form of worldmaking that results in a new global network society setting. This shift has already occurred in the tourism field, among others.

\section{Conclusion: Worldmaking and Medical Tourism}

This moment in time is showing us that the notion of local health care provision is slowly being left behind. A new global form of health care perception is on the rise and the shift has already occurred in the tourism field. Different stakeholders within medical tourism are responsible for its worldmaking capacity. We must keep in mind that the tourism industry is playing a decisive market role here. Before this could come to fruition, a rupture had to take place in the struggle between the notion of local health care and the global aspirations of medical tourism. The era of the medical institution in your neighborhood or country is still with us, but little shifts and "petites ruptures" are evident in the media and in everyday life for people all around the world. This new field of knowledge, which covers elements of health care, tourism, cultural studies, and social sciences, is open for exploration. Tourism as a field of production for practice and knowledge is entering an era of standardization and professionalization because of the reactive boundaries with other areas of expertise. We should be aware of its capacity to shape and create worlds, both in an unethical (Hollinshead, 2007) as in a progressing, positive mode, as we have discussed in this article.

\section{References}

Bhabha, H. J. (1994). The location of culture. London/New York: Routledge.

Bies, W., \& Zacharia, L. (2007). Medical tourism: Outsourcing surgery. Journal of Mathematical and Computer Modelling, 46, 1144-1159.

Boissevain, J. (1996). Coping with tourists: European reactions to mass tourism. Providence, RI: Berghahn Books.

Bourdieu, P. (2004). Science of science and reflexivity. Cambridge: Polity Press.

Castells, M. (2000). The information age: Economy, society and culture (Vols. I, II, and III). Oxford, MA: Blackwell Publishers.

Chambers, P., \& Curts, L. (1996). The post-colonial question: Common skies, divided horizons. London/New York: Routledge.

Clifford, J. (1986). Writing culture. Berkeley: University of California Press.

Cohen, E. (1979). A phenomenology of tourist experiences. The Journal of the British Sociological Association, 13(2), 179-201.

Cohen, E. (2008). Medical tourism in Thailand. AU-GSB ejournal, 24-37.

Connell, J. (2005). Medical tourism: Sea, sun, sand and ... surgery. Tourism Management, 27, 1093-1100.

de Tocqueville, A. $(1835,1840,1968)$. De la démocratie en Amérique. Paris: Gallimard.

Featherstone, M. (Ed.). (1990). Global culture. Nationalism, globalization and modernity (A Theory, Culture \& Society special issue). London: Sage.

Foucault, M. (1961). Folie et déraison. Histoire de la folie à l'age classique. Paris: Gallimard.

Foucault, M. (1963). Naissance de la Clinique. Paris: Galien.

Foucault, M. (1969). L'archéologie du savoir. Paris: Gallimard.

Foucault, M. (1975). Surveiller et punir. Naissance de la prison. Paris: Gallimard.

Foucault, M. (1976). Histoire de la sexualité (Vol. I). Paris: Gallimard.

Foucault, M. (1984a). Histoire de la sexualité (Vol. II). Paris: Gallimard.

Foucault, M. (1984b). Histoire de la sexualité (Vol. III). Paris: Gallimard.

Geertz, C. (1983). Local knowledge: Further essays in interpretive anthropology. New York: Basic Books. 
Geertz, C. (1993). The interpretation of culture. London: Fontana Press.

Giddens, A. (1991). Modernity and self-identity. Self and society in the late modern age. Cambridge: Polity Press.

Garud, A. D. (2005). Medical tourism and its impact on our health care. National Medical Journal of India, 18(6), 318-319.

Hall, S., \& du Gay, P. (1996). Questions of cultural identity. London: Sage.

Hannerz, U. (1993). Cultural complexity. Studies in the social organisation of meaning. New York: Columbia University Press.

Hazarika, I. (2010). Medical tourism: Its potential impact on the health workforce and health systems in India. Health Policy and Planning, 25, 248-251.

Hollinshead, K. (1998). Tourism, hybridity, and ambiguity: The relevance of Bhabha's 'third space' cultures. Journal of Leisure Research, 30(1), 121-156.

Hollinshead, K. (2007). 'Worldmaking' and the transformation of place and culture: The enlargement of Meethan's analysis of tourism and global change. In I. Ateljevic, A. Pritchard, \& N. Morgan (Eds.), The critical turn in tourism studies: Innovative research methodologies. Amsterdam: Elsevier.

Hollinshead, K. (2009a). Tourism and the social production of culture and place: Critical conceptualizations on the projection of location. Tourism Analysis, 13, 639-660.

Hollinshead, K. (2009b). The "worldmaking" prodigy of tourism: The reach and power of tourism in the dynamics of change and transformation. Tourism Analysis, 14, 139-152.
Kuhn, T. S. (1962). The structure of scientific revolutions. Chicago: The University of Chicago Press.

Lakatos, I. (1965). Falsification and the methodology of scientific research programmes. In I Lakatos \& A. Musgrave (Eds.), Criticism and the growth of knowledge (pp. 91-197). Cambridge, UK: Cambridge University Press.

Latour, B. (1987). Wetenschap in actie. Amsterdam: Ooievaar Pockethouse.

Lunt, N., Hardey, M., \& Mannion, R. (2010). Nip, tuck and click: Medical tourism and the emergence of web-based health information. The Open Medical Informatics Journal, 4, 1-11.

Newman, B. Y. (2006). Medical tourism. Optometry, $77(12), 581$.

Picard, M. (1996). Bali: Cultural tourism and touristic culture. Singapore: Archipalago Press.

Ramirez de Arellano, A. B. (2007). Patients without borders: The emergence of medical tourism. International Journal of Health Services, 37(1), 193-198.

Spivak, G. (1999). A critique of post-colonial reason. Cambridge, MA/London: Harvard University Press.

Turner, L. (2007). Medical tourism: Family medicine and international health related travel. Canadian Family Physician, 53, 1639-1641.

United Nations Development Programme. (2010). UNDP in action 2009/2010; delivering commitments. New York: Office of Communication/Partnerships Bureau United Nations Development Programme. 